\title{
El diablo de lo sublime. Preciosismo y clasicismo en la poética revolucionaria de Jorge Cuesta
}

\author{
The Devil of Sublime. Preciosity and Classicism \\ in Jorge Cuesta's Revolutionary Poetics
}

Vicente de Jesús Fernández Mora*

Resumen:

"El diablo en poesía" es un pequeño texto escrito por Jorge Cuesta en 1934 que tiene como excusa el comentario de la poesía de su amigo Xavier Villaurrutia. El artículo, en que puede verse un seguimiento de la ofensiva contra el nacionalismo que había emprendido durante el desarrollo de la famosa polémica sobre literatura y nacionalismo de dos años antes, fue publicado en el diario El Universal. En él nuestro autor arroja unas cuantas ideas fundamentales para entender su poética, siguiendo la estrategia de arrogarse el atributo de revolucionario para su personal forma de entender el arte. Jorge Cuesta se vincula a la tradición poética que surge con la lectura que hacen los franceses de la teoría poética de Edgar Allan Poe y que aúna al anhelo de Absoluto, procedente del romanticismo, en el contexto de una moderna sociedad desacralizada, otros elementos de sesgo desrromantizado como el concebir la práctica poética como un ejercicio cuasi científico, dotado de premeditación y cálculo. A partir de estas premisas, Cuesta desarrolla una muy personal teoría poética que resignifica términos de la tradición (clasicismo, romanticismo y preciosismo) en favor de la defensa

\footnotetext{
*Universidad Autónoma de Aguascalientes.
} 
de una forma de arte purista que estaban practicando él mismo y sus amigos del grupo Contemporáneos.

Palabras clave:

Poesía, revolución, tradición, preciosismo, clasicismo.

\section{Abstract:}

"The devil in poetry" is a short text by Jorge Cuesta written, in 1934, as a commentary on his friend Xavier Villaurrutia's poetry. The article, which continued the stance against Nationalism that he had undertaken two years before during the famous controversy on Literature and Nationalism, was published in the newspaper El Universal. In it, our author exposes a few fundamental ideas to understand his poetics, presenting himself as a revolutionary when it comes to his own personal way of understanding art. Jorge Cuesta links himself to the poetic tradition that emerges with the French interpretation of the poetic theory of Edgar Allan Poe; which combines the yearning for the Absolute — coming from Romanticism - within the context of a modern desacralized society, with other elements of unromanticized bias, such as conceiving poetic practice as a quasi-scientific exercise, endowed with premeditation and calculation. From these premises, Cuesta develops a very personal poetic theory that resignifies terms of the tradition (classicism, romanticism and preciosity) in favor of defending the purist art form that he and his friends of the Contemporaries group were practicing.

Keywords:

Poetry, Revolution, Tradition, Preciosity, Classicism.

Una de las estrategias de Cuesta en "El diablo de lo sublime" será la de arrogarse el discutido atributo de revolucionario para su personal forma de entender el arte. Si, desde la perspectiva cuestiana, los nacionalistas exigen un arte que sea fiel reflejo de los sucesos revolucionarios, un arte que sea revolucionario por contener la crónica de los sucesos, los avatares y los sufrimientos del pueblo, para Cuesta y los Contemporáneos lo revolucionario en el arte no viene 
dado por adscribir contenidos específicos que muestren una realidad revolucionada, una sociedad política y socialmente convulsionada, y un pueblo comprometido con los ideales emancipatorios, sino que el arte es revolucionario porque su propio gesto, su propia dinámica es subversiva, inconformista, rebelde. Con la intención de trasladar esta idea a su definición de poesía, nos dice Jorge Cuesta sobre el concepto de lo revolucionario que:

la revolución es el producto de la inconformidad . . . la revolución es lo que va contra la naturaleza . . . la naturaleza es la costumbre, y la costumbre es la conformidad. Todo naturalismo es, estrictamente, un conformismo. Y en ningún conformismo puede verse nunca una revolución. Lo revolucionario es lo que va contra la tradición, contra la costumbre; es el pecado, la obra del demonio. (244)

Si de un lado están el naturalismo, la conformidad, lo moral, el bien y la costumbre, del otro lado, opuestos a esta serie de términos que sugieren normalidad o estabilidad, están el mal, la rebeldía, el pecado, el inconformismo, el diablo y la revolución. Sin duda que este texto está entre aquellos de Cuesta que permiten una lectura más cercana al nihilismo o al posmodernismo epistemológico, dado que aquí parecen exaltarse valores de pura negatividad frente a cualquier forma de poder o saber instituido, frente a toda forma de costumbre o conformismo con el status quo ético o estético.

Si bien la pretensión de Cuesta es, como decimos, recalar en el arte con objeto de hacer una lectura particular de la tradición poética moderna, el verdadero valor de lo revolucionario es de tipo epistemológico o cultural: la revolución es lo que se opone, lo que se rebela frente a la inercia de la costumbre, frente al peso esclerotizante de la tradición, frente a las formas impositivas del discurso político. Este sentido de lo revolucionario, abstraído de sus realizaciones concretas políticas o artísticas, será un eje central del pensamiento cuestiano. Aparecerá a lo largo de sus escritos, aplicado a las distintas batallas culturales en las que se embarcará, como el principio rector de un inconformismo individualista incapaz de 
congraciarse con ninguna preceptiva que recete dogmas emanada desde los centros de poder institucional o desde las narrativas canónicas de la tradición ${ }^{1}$ :

El demonio es la tentación, y el arte es la acción del hechizo, . . . solo el diablo está detrás de la fascinación, que es la belleza. Por esta causa, es imposible que haya un arte moral, un arte de acuerdo con la costumbre ... es imposible que el arte se conforme con lo natural. Y lo extraordinario es lo único que fascina. He aquí por qué son inseparables el diablo y la obra de arte, la revolución y la poesía: No hay poesía sino revolucionaria, es decir, no la hay sin "la colaboración del demonio". (244-45)

Vittoria Borsò dice que “"poder revolucionario’ de la poesía quiere decir para los románticos alemanes una fuerza energética, no un objetivo político que se podría representar dentro del marco de una obra poética" (7). Es en este sentido en el que puede entenderse el revolucionarismo que Cuesta encuentra en el arte y especialmente en la poesía: un diabolismo como forma de permanente puesta en entredicho de los valores instituidos, como forma de conocimiento que se aventura a explorar nuevos espacios de la realidad y la percepción y que, por tanto, supone, por su propio accionar desafiante, una amenaza diabólica frente a las instituciones que detentan el poder de decidir cuáles son los valores y normas aceptadas.

El arte, la poesía, volviéndose una práctica crítica, no puede sin embargo dejar de cumplir al mismo tiempo una función política.

${ }^{1}$ Si la Revolución será para Cuesta más epistemológica o ideológica que social, su rebeldía igualmente será más intelectiva o programática que formal, lo que se refleja en una poesía que, si bien huye de la representación y el realismo, trabaja y elabora con respeto de las formas clásicas. Como dice Selena Millares: "Curiosamente, esa rebeldía que preconiza Cuesta no se identifica con una poética experimental y una ruptura de las formas canónicas. Su subversión es de índole intelectual, en un regreso a lo clásico a través de modelos como el de Valéry y Mallarmé, con su escritura esencializada y libre de ornamento” (80). 
Pero este criticismo, que para Cuesta es inherente a la verdadera actividad artística, no puede venir de la mano de la replicación de lo natural, pues esto no sería más que un conformismo con los dictados de una realidad coercitiva que se impone a la libertad creativa. El diabolismo del arte ha de superar las limitaciones de la mera representación y solo a través de la experimentación creativa anticonvencional puede romper vínculos con los códigos establecidos de comunicación y comunidad y hacer aflorar nuevas discursividades que invierten o desafían las estructuras dominantes de la razón política. Como dice Vicente Quirarte, para Cuesta:

La poesía es el acto rebelde, subversivo, del hombre que se enfrenta, con todas sus limitaciones, al Creador, y pretende concebir un Verbo que se acerque al instante de la encarnación; por eso Cuesta afirma, como Nietzsche, el carácter antinatural y, por ende, revolucionario, de toda obra de arte. (21)

Desde esta perspectiva la poética es una fuerza capaz de construir verdades alternativas al discurso dominante, no tanto, repetimos, mediante la adscripción de programas políticos explícitos en sus lenguajes artísticos, sino a través de la configuración de nuevas sensibilidades diversas y antagónicas al modelo hegemónico. Aquí hay desde luego una defensa, por parte de Cuesta, del arte no mimético, que será mucho más clara y explícita en su crítica de la pintura moderna. Cuesta equipara representación de la realidad, que en este momento de revolucionarismo artístico oficializado quiere decir concretamente nacionalismo y mexicanismo, novela de la Revolución y muralismo, con la aquiescencia frente al mandato oficial, pues, siguiendo de nuevo a Borsò, "manteniendo las premisas de la mímesis, la sólida base del discurso de la política sobre la realidad queda intacta; aún más, la política usa la poesía para legitimar su sistema discursivo" (8-9). Es por esto que el ejercicio poético, para Cuesta, escapa a lo determinado, incursiona por terrenos no previstos por el estado de cosas, es aventura y riesgo que elude la costumbre y la seguridad, pone al descubierto las fallas de un sistema explicativo pretendidamente completo y abre posibilidades hacia nuevas formas del ser individual y de la identidad social. 
Partiendo de una negación muy explícita a un programa político-estético nacionalista, que su pensamiento universalista rechaza terminantemente, las lucubraciones de Cuesta sobre el tema que le preocupa lo llevan normalmente a radicalizar sus argumentos y a profundizar en las aporías con las que se cruza, por lo que plantea problemas que alcanzan el grado de lo filosófico, yendo mucho más allá del argumento circunstancial que alentó la discusión. El arte, la poesía, según entendemos de sus propias palabras, se desprende "de toda realidad", "de toda seguridad", se confía "a la aventura imprevisible de la inteligencia", no teme los "abismos que a cada paso se abren", lo único que ahí no tiene cabida "es la costumbre" y "como todo temperamento revolucionario, es el temperamento de la excepción y el peligro" (247). La poesía se aleja, pues, de todo lo representable, no se ajusta a las estructuras racionales existentes, a los sistemas explicativos previos, a la realidad de la que paradójicamente nace, sino que genera, más bien, su propia ética fuera de la moral convencional. Por esto nos atrevemos a decir que la estética cuestiana anuncia la estética de lo sublime de Lyotard.

Para el filósofo francés, la estética de la modernidad es la estética de lo impresentable, que parte de la creencia y el descubrimiento de "lo poco de realidad que llena la realidad, descubrimiento asociado a la invención de otras realidades" (70). La realidad se agota inevitablemente a la hora de expresar con los recursos propios de un arte representacional, mimético o figurativo, ideas que la exceden. Por eso el artista ha de apurar los límites de la representación, experimentar con nuevas formas y formatos para tratar de representar lo que en último término es irrepresentable. Ideas de totalidad, de absoluto, de sentido, de plenitud, de libertad, de belleza, desbordan las posibilidades de los recursos de la estética disponibles, los marcos éticos y de la costumbre. Por tanto, el poeta debe buscar y elaborar más allá de la apariencia de las cosas en su intento, siempre frustrado, de hacer visible, comprensible, lo que inevitablemente escapa a las posibilidades de la imaginación y de la inteligencia.

La poesía es, por tanto, lo que se encuentra más allá del nivel inmediato de la experiencia, más allá de las apariencias; es una alusión, una incitación hacia otras realidades que el poeta crea como 
representación frustrada de lo imposible. Como dice Merlin H. Forster, la poesía en la concepción cuestiana es "una forma extremada de estilización en que el mundo se transforma para cobrar nuevos límites, y por medio de la cual el artista puede investigar y expresar nuevas relaciones" (107). Se trata, entendemos, del límite al que tiende la poesía pura en la teoría de Valéry, un límite que actúa como faro rector del poema, pero que a la vez es siempre inalcanzable, pues "nada tan puro puede coexistir con las condiciones de la vida" (Teoría 19). Se trata de un accionar sobre o contra la realidad para acceder y crear otras realidades que satisfagan aunque sea precariamente, como "promesa de otro gozo mejor" (Cuesta 148), la atracción de la tentación del ideal. Como dice el filósofo Nicolás Grimaldi, "lo propio del arte es hacer deseable lo que nos hubiera dejado indiferentes en la realidad. El arte, por tanto, es una seducción. La serpiente de la tentación era artista” (13). Revolución, estado de excepción, sublime, son categorías que pueden explicar la estética-política de Cuesta. En "El diablo en poesía", texto central de la poética cuestiana, poesía y revolución son términos casi intercambiables, pues ambos aluden a lo que está más allá de las posibilidades de la representación, a lo que está inconforme con el marco cognoscitivo y político de la situación dada y, además, aspiran a penetrar en lo "remoto y profundo".

La revolución y la poesía encarnan el perpetuo inconformismo con lo dado. Son diabólicas en el sentido en que desafían los códigos de la comunidad, trascienden los marcos de sentido convencionales y se rebelan contra toda forma de representación estabilizada por el orden vigente moral, político o estético. Jorge Cuesta, en su teoría, está a un paso, sino ya del todo inmerso, en el nihilismo nietzscheano; y, si bien, como apuntábamos arriba, en sus creaciones poéticas prefiere utilizar las formas de la tradición clásica, en sus desarrollos teóricos vislumbra o insinúa posiciones que lo colocan como un antecedente de la sensibilidad posmoderna:

Un artista, un escritor posmoderno, están en la situación de un filósofo: el texto que escriben, la obra que llevan a cabo, 
en principio, no están gobernados por reglas ya establecidas, y no pueden ser juzgadas por medio de un juicio determinante, por la aplicación a ese texto, a esa obra, de categorías conocidas. Esas reglas y esas categorías son lo que la obra o el texto investigan. El artista y el escritor trabajan sin reglas y para establecer las reglas de aquello que habrá sido hecho. De ahí que la obra y el texto tengan las propiedades del acontecimiento. (Lyotard 73) ${ }^{2}$

Cuesta, en su concepción diabólica de la poesía, no hace sino instalarse en una tradición poética de la modernidad que comienza con Poe y que se desarrolla con Baudelaire, Mallarmé y Valéry, para la que el diablo es, como dice Salvador Elizondo, "el representante simbólico del espíritu de la literatura (8)". La función develadora de otra realidad oculta bajo la apariencia, de otro sentido distinto al convencional, que es insatisfactorio para la sed de ideal del poeta, así como la noción de la poesía como el instrumento para, al menos, intentar el "conocimiento de la realidad última" y del "arte como la búsqueda a tientas del ideal", del Absoluto son sin duda atribuciones que la estética moderna hereda del romanticismo. Para este, la imaginación y la intuición eran las potencias principales del poeta para conocer lo real y descifrar la naturaleza, para así liberar "la verdad que en ella adormece" (Wellek 103-52), que se esconde bajo la superficie de una realidad precaria e insuficiente.

Tales premisas, que surgen de la reacción romántica frente al mecanicismo y racionalismo del clasicismo, van a estar presentes en toda la poesía moderna, a pesar de las muy diferentes formas antirrománticas que esta acoge a lo largo de todas las vicisitudes por las que atraviesa la creación artística durante la segunda mitad del siglo

2 "Para nuestro autor, lo sagrado surge dentro del nuevo cosmos propuesto por la posmodernidad, donde es eminente la muerte de Dios, y, con Heidegger, se puede ver que "la obra es la mediación a través de la cual puede llegarse a lo sagrado"' (Velasco 173). 
XIX y el siglo XX. ${ }^{3}$ Dice Hugo Friedrich, en su clásico tratado sobre la poesía moderna, que el romanticismo:

se extinguió a mediados del siglo XIX, pero perduró como destino espiritual de generaciones posteriores, incluso de aquellas que creían liquidarlo e imponer otras modas. Lo que en él había de desmesura, de afectación, de ampulosidad, de sentimentalismo deleznable y trivialidad, desaparecía . . . El romanticismo, incluso cuando muere, deja impresos sus estigmas en sus herederos. Éstos se rebelan contra él precisamente porque sienten su influjo. La poesía moderna es romanticismo desromantizado. $(38-39)^{4}$

En las realizaciones poéticas de Cuesta está muy presente esta búsqueda de la permanencia. Como intento exasperado por apresar la fijeza del instante frente a la precariedad evanescente del espacio y la materia sometidos al efecto implacable del paso del tiempo, en un contexto en que han sido desacralizados los discursos transcendentales tradicionales, esta dolorosa inquietud por, decimos, asir poéticamente la permanencia, aparece una y otra vez, con insistencia obsesionante, como principal preocupación en sus sonetos, o como epifanía final en que se resuelve esa búsqueda de sentido en el encuentro con la palabra poética, en que puede resumirse su ambicioso poema Canto a un dios mineral. Al caso dice Grant Sylvester: "Cuesta descubre que es un lenguaje esencial — la poesía misma - lo que da unidad, propósito y permanencia al ser". La

${ }^{3}$ Esta es la tesis central de Los hijos del limo de Octavio Paz: "El tema de este libro es mostrar que un mismo principio inspira a los románticos alemanes e ingleses, a los simbolistas franceses y a la vanguardia cosmopolita del siglo XX" (24). Muchas de las ideas centrales de este libro son claramente deudoras del clásico Estructura de la lírica moderna de Hugo Friedrich, que Paz nunca cita.

${ }^{4}$ Cuesta, treinta años antes, ya adelantaba el carácter desromantizado del arte moderno, es decir liberado de la nota sentimental, de la retórica excesiva, de la referencia a la realidad inmediata, cuando anunciaba que la virtud del preciosismo artístico no "es dehumanizar, sino desromantizar la realidad" (90). 
poesía moderna, con Baudelaire y Poe a la cabeza, si bien mantiene los presupuestos románticos de tensión hacia lo Absoluto, se derromantiza principalmente a través del cálculo y la premeditación en la composición del poema, que Valéry va a teorizar como el procedimiento clásico por excelencia.

En el conocido texto "La situación de Baudelaire", que sin duda era conocido por Cuesta, el poeta francés dice que:

Los románticos habían descuidado todo, o casi todo lo que demanda al pensamiento una atención y una continuidad un tanto penosas. Ellos buscaban los efectos de choque, de atracción y de contraste. No les atormentaban excesivamente la medida, ni el rigor, ni la profundidad. Les repugnaban la reflexión abstracta y el razonamiento, y no solamente en sus obras, sino también la preparación de sus obras -lo que es infinitamente más grave. (Variedad 118)

Cuesta sigue las ideas de Valéry y concretamente las de este texto, que seguramente conoció en el original, publicado en francés por primera vez en 1924 y reeditado dos años después como introducción a Las flores del mal. Ya en el artículo "Notas", publicado en octubre de 1927 en la revista Ulises, planteaba Cuesta esta genealogía de la poesía moderna que arrancaría con las sugerencias teóricas de Poe, seguiría con los logros de Baudelaire y Mallarmé, y alcanzaría sus últimas consecuencias en la estética de la poesía pura de Valéry.

Cuesta interpreta a Poe según las sucesivas lecturas que la crítica francesa ha hecho de su poética, identificando en el norteamericano por primera vez la actitud de ejercer el oficio poético como un procedimiento científico perfectamente consciente y deliberado. Este último pensamiento apareció esbozado en algunos de los ensayos de Poe, especialmente en aquel famoso de La filosofía de la composición, con el que pretendidamente trata de explicar el proceso compositivo utilizado para la construcción metódica de su famoso poema El cuervo. Dice Valéry que la curiosidad del genio de Baudelaire lo llevó a: 
descubrir en las obras de Edgar Allan Poe un nuevo mundo intelectual. El demonio de la lucidez, el genio del análisis, y el inventor de las más nuevas y seductoras combinaciones de la lógica con la imaginación, del misticismo con el cálculo, el psicólogo de la excepción, el ingeniero literario que profundiza y utiliza todos los recursos del arte. (Variedad 110)

Cuesta dirá unos años después, en el artículo citado, que:

es Edgar Allan Poe el primero que se vale de tal artificio para oponerse a la literatura romántica. Emplea, primero que nadie, un orden meditado que organiza sobre una misma finalidad los objetos reunidos en la obra artística que emprende. Logra ocultar la naturaleza de cada sentimiento, de cada personaje con el oficio que un propósito calculado les impone . . La crítica de Poe no está lejos de parecer una pura actitud científica, una actividad intelectual que se ejerce sobre un objeto perfectamente delimitado por el cálculo. (91-92)

A todo el acarreo romántico de la poesía como develación, como forma privilegiada del conocimiento de la realidad más allá de la apariencia, como búsqueda normalmente exasperada y frustrada de sentido o de Absoluto, así como a la labor primitiva de la imaginación y/o la intuición como la punta de lanza de esta forma poética esclarecida de conocer, lo que la tradición asentada en Poe por los poetas franceses añade, para configurar el modelo de buena parte de la poética moderna, es la técnica y la composición.

Según el profesor del Prado Biezma, el aspecto más importante de la relación entre Poe, Baudelaire y Mallarmé es:

la presencia de Poe en la configuración técnica del hecho poético para la modernidad occidental; presencia cuya aportación fundamental (siempre vía Baudelaire y Mallarmé) la podríamos resumir en la confrontación entre la naturaleza del genio y el trabajo de composición que exige el acto literario en general y el poético (sobre todo el poético) en particular. (114) 
Valéry teorizará sobre esto una y otra vez, negando un total dominio por parte de la gracia y la intuición sobre el mundo poético e insistiendo en el trabajo arduo, tortuoso, paciente del intelecto sobre la materia prima que ofrece la sensibilidad. También para Jorge Cuesta está aquí el hecho fundacional de la poesía moderna.

La autoconciencia del quehacer poético, la poesía como ciencia de la composición en la que ningún detalle puede quedar al azar o a la improvisación, en la que la inspiración no excluye el rigor y la lucidez del trabajo reflexionado y plenamente consciente ${ }^{5}$, están en la base, con Baudelaire como su genio iniciador, de la poesía estrictamente moderna. $\mathrm{Al}$ respecto, Cuesta señala que la

concepción baudelaireana se ha hecho inseparable de la conciencia poética. Lo que se llama 'poesía moderna' a Baudelaire debe la novedad revolucionaria de su carácter. 'Poesía moderna’ significa, en rigor, poesía posterior a Baudelaire. (245)

Esta concepción alcanza su límite de reflexividad con la teoría y práctica poética de Paul Valéry, a quien T. S. Eliot llamaba "el más autoconsciente de todos los poetas" y de quien Cuesta toma directamente, como decimos, algunas de sus ideas fundamentales:

Son dos las ideas que han sido llevadas a su culminación por Valéry, y que podemos remontar hasta Poe. Está primero la doctrina, tomada de Poe por Baudelaire, que ya he citado: "un poema solo puede tenerse a sí mismo en el horizonte"; segundo, la noción de que la composición de un poema ha de ser tan

5 "Los poemas cuya compleja perfección y afortunado desarrollo impondrían con mayor fuerza a sus maravillados lectores la idea del milagro, del golpe de suerte, de realización sobrehumana (debido a una conjunción extraordinaria de las virtudes que se pueden desear pero no esperar encontrar reunidas en una obra), son también obras maestras del trabajo, son, además, monumentos de inteligencia y de trabajo continuado, productos de la voluntad y el análisis, que exigen cualidades demasiado múltiples para poder reducirse a las de un aparato registrador de entusiasmos o de éxtasis" (Valéry, Teoría 153-54). 
consciente y deliberada como sea posible, que el poeta debe observarse a sí mismo en el acto de la composición. (Eliot 340)

Cuesta recibe de Valéry la tradición de la poética moderna que se ha ido desarrollando a partir de las sugerencias de Poe, y de las reelaboraciones e interpretaciones de estas hechas por parte de Baudelaire y Mallarmé ${ }^{6}$, que aúnan la herencia romántica de la poesía como religión sin dios, como energía visionaria y revolucionaria capaz de traspasar las costras de la costumbre y develar realidades ocultas bajo las apariencias, con el ejercicio científico sistemático y reflexivo. A medida que esta tesis se extrema en el autor de El cementerio marino, la creación poética es desbastada de todo residuo improvisador y retórico, mediante la depuración del producto artístico de todo exceso romántico y de "todo aditamento que no sea su propia poeticidad” (Prado 117). Como dice Kenia Aubry, para Cuesta:

el arte es un método de análisis, de investigación, por medio del cual lo oculto tiene oportunidad de revelarse, no desconoce que el arte dota de un sentido nuevo al mundo, que en el arte, ya lo ha dicho Heidegger, emerge la verdad. Esto constituye el trazo fundamental de su estética, y lo repetirá de distintas maneras a lo largo de su obra. (54)

Cuesta, lo repetimos, sigue muy de cerca a Valéry, quien puede considerarse, junto con Nietzsche y Gide, una de sus mayores influencias. El autor francés, en su mencionado texto "La situación de Baudelaire", hace una serie de generalizaciones desde las que debemos entender el sentido que en la obra, y también en el pensamiento de Cuesta, adquieren términos como romántico y clásico.

${ }^{6}$ Hay que tener en cuenta que estas interpretaciones de Poe han inspirado muchas cautelas entre los críticos de lengua inglesa, como Eliot (en el artículo antes citado) o Aldous Huxley. Anthony Stanton dice que "los lectores de lengua inglesa consideramos más bien una invención la interpretación de Mallarmé y Baudelaire a partir de Poe" (144). 
Valéry trata de hacer derivar los logros teóricos y poéticos de Poe y Baudelaire de una oposición al romanticismo, exacerbando los defectos y excesos de este con el objeto de legitimar una tradición poética culta y reflexiva que llegaría hasta él mismo.

$\mathrm{Al}$ romanticismo como movimiento, in toto, le son adjudicados atributos de espontaneidad, descuido, retoricismo, gesticulación oratoria, elocuencia, desbordamiento emotivo, falta de rigor, diletantismo, fraseología. A estos poco honrosos títulos poéticos se les opone la tradición que nace con la enseñanza que Baudelaire recoge del americano Poe, y que sustituye, en síntesis, "una acción espontánea por una acción reflexiva” (Valéry, Teoría 113). El autor de Las flores del mal, aunque de origen romántico, por reaccionar contra estos excesos de la escuela en la que se formó, queda caracterizado como un clásico. A partir de ahí, la noción de escritor clásico que ostenta Valéry es: "el escritor que lleva dentro a un crítico, y que lo asocia intimamente a sus trabajos" (Teoría 116). Acto seguido, elabora una teoría según la cual todo clasicismo vendría después de un romanticismo previo, de forma que "la esencia del clasicismo es venir después":

El orden supone un cierto desorden al que él viene a reducir. La composición, que es artificio, sucede a cierto caos primitivo de intuiciones y de desarrollos naturales. La pureza es el resultado de operaciones infinitas sobre el lenguaje, y el cuidado de la forma no es nada más que la reorganización meditada de los medios de expresión. Lo clásico implica, por tanto, actos voluntarios y pensados que modifican una producción "natural" según una concepción clara y racional del hombre y del arte. (117)

Es claro que Valéry utiliza las categorías historiográficas en un sentido amplio, tipológico y no exclusivamente histórico, con lo que sugiere la existencia de alternancias cíclicas en la historia del arte. De modo genérico, también Cuesta, siguiendo en esto fielmente a Valéry, parece asociar romántico con escuelas artísticas distintas a toda la tradición del arte literario originada en la Antigüedad Clásica, es decir, con corrientes de rechazo a las normas y reglas clásicas, 
en analogía con contrastes estéticos que habían sido comunes en la crítica de los siglos XVII y XIX: entre antiguos y modernos, entre poesía artificial y poesía natural o popular, entre el drama barroco y la tragedia clásica francesa o entre lo gótico y lo clásico (Wellek 106). La formulación más importante de este contraste fue la que dio A. W. Schlegel en las conferencias dictadas en Viena en 1808-1809. En ellas "se contrastan claramente la literatura de la Antigüedad y la del neoclasicismo (principalmente la francesa), con el drama romántico de Shakespeare y Calderón, la poesía de la perfección con la poesía del anhelo infinito" (Wellek 109). Cuesta, sin embargo, va más allá de esta tradicional dicotomía simple y elabora su propia versión de la poética moderna introduciendo un concepto en la terna que no aparecía en la reflexión de su maestro: se trata del preciosismo.

Según Cuesta, la "función" antirromántica corresponde al preciosismo artístico, cuya tarea es "desromantizar la realidad", siendo esta la etapa que se opone con un gesto de artificiosidad al romanticismo y la que realmente precede a un clasicismo moderno. Cuesta plantea un paralelismo entre el preciosismo histórico del siglo XVII y el arte contemporáneo, en tanto que en ambos momentos, a su parecer, el arte busca, mediante la perfección formal, el autoconfinamiento en su propia artisticidad con objeto de huir de un exceso de naturalismo. Cuesta se pregunta si no son semejantes las intenciones del preciosismo histórico y de este que él llama preciosismo contemporáneo, cuando este último "pretende la poesía pura, la música musical y la pintura excesivamente plástica” (90), pues a ambos los une "la misma repugnancia a la naturalidad" (91). El artificio de crear mundos poéticos o artísticos que aparten la obra de arte del mundo circundante mediante un esfuerzo, quizá todavía excesivo, de antinaturalismo es seña de identidad del arte contemporáneo, que trata de defender su pureza artística mediante su preciosidad, a través de una perífrasis, de un ejercicio de negación y aislamiento frente a los excesos del antropocentrismo romántico.

El preciosismo contemporáneo es, desde la perspectiva cuestiana, una época de transición, una preparación de las virtudes afirmativas del clasicismo, tal como el preciosismo francés fue la antesala y en cierta forma preparó el auge del clasicismo de Racine o Cor- 
neille; "entretanto", dice Cuesta, "tiene que servirse de esa lógica artificial que lo distingue para asegurar su integridad. Tiene que construirse como Góngora, como Mallarmé, como Juan Ramón Jiménez, un universo estrictamente propio" (91). Para Cuesta esta parece ser una estrategia necesaria del artista que reacciona, mediante la depuración y la individuación de su lenguaje artístico, ante la presencia esclavizadora de la pasión, es decir ante las tentaciones del naturalismo romántico, sus excesos de sentimentalismo, de retórica, de desbordamiento emocional. De este modo, el artista construye mundos hasta cierto punto herméticos, sutilizados, que tratan de inventar nuevas formas, no de huir de la realidad, no de deshumanizar el arte, sino de apresarla, de ensayar otras formas de humanizarla.

Como dijimos, pues, el ensimismado trabajo sobre la forma, la sublimación de la pureza del lenguaje, la afección por mostrar "puras maneras artificiales" que oculten el patetismo en favor de valores superiores del espíritu son rasgos que identifican a los preciosismos artísticos y que los distinguen y oponen a lo romántico:

En la actualidad, la afectación de lógica; el uso de un lenguaje "necesario"; la repugnancia a la elocuencia, a la pasión elocuente; el humorismo, equivalente, en cierto modo, del burlesco, que ridiculiza toda propensión sentimental, definen al nuevo preciosismo como una oposición a lo romántico. (Cuesta 94)

Es Edgar Allan Poe quien primero que nadie hace uso de este artificio para oponerse al romanticismo. Es Poe, cuya inclinación personal, cuyos temas e inspiración son totalmente románticos, quien rompe la dicotomía temporal arriba planteada y, sin dejar de considerar la poesía en su esencia romántica como instrumento de trascendencia espiritual y cognitiva, aplica ahora al trabajo del artista el método y la disciplina del científico. Es decir, al anhelo de infinito de la poesía romántica se le aplica el rigor intelectual y la búsqueda de perfección formal de la exigencia clásica: "La crítica de Poe no está lejos de parecer una pura actitud científica, una actividad intelectual que se ejerce sobre un objeto perfectamente delimitado por 
el cálculo” (Cuesta 91). Nos permitimos retomar esta cita cuestiana, ya incorporada arriba, con el objeto de ilustrar que, desde la perspectiva de nuestro autor, con Poe comienza el preciosismo moderno como la negación de lo romántico. Además, con su tendencia al alejamiento de todo sentimentalismo, de todo patetismo y de la búsqueda de lo exclusivamente poético, podemos deducir que se encamina a la poesía pura.

Cuesta pone aun ciertas objeciones al arte contemporáneo, o al menos al que él entiende como preciosismo, que es un arte de negación, de oposición a lo romántico y que, por esto, no puede aún desenvolverse con la libertad afirmativa del arte clásico. Cuesta se atreve a rebatir la tesis de Valéry y afirma que al arte contemporáneo "se le ha considerado también como un fruto clásico, erróneamente. Hay que tener presente que sólo es una disciplina” (96). El preciosismo se nos presenta, en la atrevida versión cuestiana, como una antesala, una preparación para el advenimiento del arte clásico, un exceso o una desmesura de rigor técnico y de artificiosidad que, en todo caso, es necesaria como previa negación o pulimento del exceso romántico. El arte, ensimismado en su preciosismo, se protege frente a la amenaza de invasión de las desmesuras sentimentales y retóricas del romanticismo edificando una fortaleza esteticista que aparentemente lo aleja de la realidad. Como en una relación física de acción-reacción -e incluso, nos atreveríamos a insinuar, como en una relación dialéctica hegeliana - al exceso romántico le responde un exceso preciosista, y solo después de depurados ambos extremos surge el verdadero clasicismo como plena libertad de afirmación creativa.

A Cuesta le molestan los excesos, los énfasis, la desmesura, el virtuosismo y el tecnicismo ensimismado. Su preferencia por un clasicismo universal no enfático, natural (no naturalista), parece recordar la herencia de ese tono medio como carácter de la poesía mexicana que defendieran Alfonso Reyes y Pedro Henríquez Ureña. El arte contemporáneo, parece decirnos Cuesta, se debate entre el preciosismo y la poesía pura, entre la negación antirromántica y la afirmación clásica: "el problema de la poesía pura planteado en los últimos tiempos fue resuelto por muchos con el puro virtuosismo 
poético" (84). Para nuestro autor el clasicismo es una superación del preciosismo, lo que contraviene la propia tesis de Valéry:

Es un error considerar al clasicismo como un estado al que el romanticismo llega, así sea por reacción. Lo contrario es lo cierto; éste es sólo una degeneración de aquél. Lo que es anterior al clasicismo es el preciosismo, un rigor artificial y exagerado. ... (El preciosismo) se recluye dentro del rigor que voluntariamente se impone: para que un día pueda libertar su crisálida. Entonces llega el clasicismo que es la libertad, la más absoluta libertad. (96)

Cuesta incluye entre los preciosistas, con mayor o menor justicia o rigor, a autores modernos y contemporáneos, como Mallarmé, Juan Ramón Jiménez, Poe, Gómez de la Serna, Pedro Salinas, Valle-Inclán, Antonio Espina, Benjamín Jarnés, Proust o Cézanne. Considera clásicos explícitamente a Gide — “¿Qué diferente Gide! ¡Oh, qué excesivamente diferente!” (96)—, a Baudelaire — "se mantiene clásico y encuentra en él (Poe) sólo un aliado literario" (92)—, suponemos que a Valéry aunque no lo señale expresamente y, como no podía ser de otro modo, para cerrar a la perfección el círculo de su desarrollo teórico, a los poetas de los Contemporáneos. Cuesta ya había hecho referencia a esta tendencia a aislar la poeticidad pura del poema y decantarla de todo agregado extrapoético en dos críticas anteriores a sendos libros de poemas de Gorostiza y Villaurrutia.

De la poesía de Canciones para cantar en las barcas (1925) de Gorestiza, Cuesta valora su "textura fina hasta lo quebradizo a fuerza de pulida y de honrada”, emparenta sus logros con la pureza juanramoniana, destaca la gracia virginal e inocente de su "ingenuidad culta", si bien esta nunca es fruto del mero arrobo o del don poético, sino que es el resultado de un trabajo paciente de destilado y de la aplicación continua de una conciencia de "jardinero". Concluye su reseña afirmando que "nunca hemos tenido en México más desinteresada poesía, ni más pura" (72). En términos comparables se expresará en su reseña de 1927 del libro Reflejos (1926) de Xavier Villaurrutia. Cuesta vuelve con la metáfora del jardín y el invernadero 
para dar cuenta de un trabajo poético sometido a unas condiciones muy controladas de atención y cuidado, de exactitud y constancia. De nuevo niega la intervención de la gracia, de la inspiración o el "sueño extraviado", en favor del oficio y la autoexigencia. Es una poesía que no aparta de sí la pasión pero que reconoce que "la pasión no es sino la región donde hay más dificultad de mantenerse sereno". De nuevo la referencia a Juan Ramón Jiménez es inevitable, con quien le emparenta una laboriosa virtud para conseguir una poesía "sobria y desnuda" (84). Podemos atrevernos a deducir que la poesía pura que Cuesta encuentra en la obra de sus amigos, y la que él mismo practicará en sus sonetos y su poema largo es la consecución clásica, libertada, del preciosismo contemporáneo.

\section{Bibliografía}

Aubry, Kenia. "Una poética del arte, los ensayos del Jorge Cuesta". La palabra y el hombre, no. 124, 2002, pp. 43-60.

Cuesta, Jorge. Obras reunidas II: Ensayos y prosas varias. FCE, 2004.

Eliot, T. S. "From Poe to Valéry". The Hudson Review, vol. 2, no. 3, 1949, pp. 327-42.

Elizondo, Salvador. "Retórica del diablo". Revista de la Universidad de México, vol. 25, no. 11, 1971, pp. 5-8.

Friedrich, Hugo. Estructura de la lírica moderna. Seix Barral, 1959.

Grant Sylvester, Nigel. "Jorge Cuesta: La imposible permanencia”. Revista de la Universidad de México, no. 11, 1977.

Grimaldi, Nicolás. "El arte y el mal”. Anuario filosófico, vol. 20, no. 2, 1987, pp. 9-22.

Lyotard, Jacques. "Qué era la posmodernidad". El debate modernidad-posmodernidad, compilado por Nicols Casullo, Retórica, 2004, pp. 65-73.

Paz, Octavio. Los hijos del limo. Seix Barral, 1990.

Prado Biezma, Javier del. "Poe, Baudelaire y Mallarmé (en el nacimiento del poema moderno)". Revista de filología de la Universidad de la Laguna, no. 28, 2010, pp. 95-121. 
Quirarte, Vicente. Perderse para reencontrarse: Bitácora de Contemporáneos. UAM, 1985.

Stanton, Anthony. Inventores de la tradición: ensayos sobre poesía mexicana moderna. El Colegio de México / FCE, 1998.

Valéry, Paul. Teoría poética y estética. Visor, 1990.

- - -. Variedad I. Losada, 1956.

Velasco, Raquel. "Jorge Cuesta: Un rebelde que insisten en llamar loco". La Palabra y el Hombre, no. 117, 2001, pp. 159-177.

Wellek, René. Conceptos de crítica literaria. Ediciones de la Biblioteca de la Universidad Central de Venezuela, 1968. 